\title{
FASES, IMPULSOS E CICLOS MAGMATICOS EM COMPLEXOS GRANITÓIDES ASSOCIADOS COM FALHAS TRANSCORRENTES, SP
}

\author{
EBERHARD WERNICK*, PAUL K. HÖRMANN**, ANTÓ NIO C. ARTUR*, CLÁUDIO J. FERREIRA.***, \\ TAMAR M.B. GALEMBECK*, ANTÓNIO M. GODO Y*, e FABIO R.D. ANDRADE*****
}

\begin{abstract}
MAGMATIC PHASES, IMPULSES AND CYCLES IN GRANITOID COMPLEXES ASSOCIATED WITH TRANSCURRENT FAULTS, SP, BRAZIL. Comparativo study of six granitoid complexes associated with transcurrent faults in the State of São Paulo, Brazil, concerning their architecture and magmatic cycles is presented. Three of these complexes are calc-alkaline (Itaqui, São Roque, Cantareira) and the other three are rapakivi ones (São Francisco, Sorocaba, Itu). The architecture of the complexes is the result of the coalition of severa! magmatic phases with the following temporal emplacement sequence: 1 . Early Phase; 2. Main Phase; 3. Early Lateral Accretionary Phase; 4. Phase of Stocks and Circular Intrusions; 5. Final Lateral Accretionary Phase. Also the magmatic units whiçh built up the complexes belong to at least two magmatic cycles with or without an intra-cycle mafic dike phase. The recurrence of the architecture style and the presence of successive magmatic cycles in ali complexes independently of their serial character is discussed in terms of magma emplacement mechanisms, the presence of collecting magma chambers successively tapped and recharged and the reactivation-phases of the transcurrent faults to which the complexes are associated.
\end{abstract}

Keywords: Magmatic cycles, granitoid complexes, transcurrent faults, Late Precambrian, Geochemistry, Main Elements.

\begin{abstract}
RESUMO É apresentado um estudo comparativo da arquitetura e da sequência temporal dos impulsos magmáticos de seis complexos granitóides associados com falhas transcorrentes no Estado de São Paulo. Três destes complexos são cálcio-alcalinos (Itaqui, São Roque, Cantareira) e três são rapakivi (São Francisco, Sorocaba, Itu). Os complexos têm sua arquitetura dada pela coalescência de várias fases magmáticas, cuja sucessão temporal é a seguinte: 1. Fase precoce; 2. Fase principal; 3. Fase de acresção lateral inicial; 4. Fase de colocação de stocks e intrusões circulares que cortam principalmente as unidades magmáticas da fase principal; 5. Fase de acresção final. Todos os complexos mostram, também, a presença de pelo- menos dois ciclos magmáticos, separados ou não por uma fase de intrusão de diques enriquecidos em minerais máficos. A recorrência da arquitetura e de sucessivos ciclos magmáticos em complexos com distintas características seriais (cálcio-alcalinas ou rapakivi) são discutidos baseando-se no mecanismo de ascensão magmática, da existência de câmaras coletoras sucessivamente drenadas e recarregadas e nas fases de reativação das falhas transcorrentes, com as quais os complexos se associam.
\end{abstract}

Palavras-chave: Ciclos magmáticos, complexos granitóides, falhas transcorrentes, Pré-Cambriano Superior, Geoquímica, Elementos Maiores.

INTRODUÇÃO A ascensão por flutuação e por propagação de diques são os principais mecanismos de movimentação de magmas granitóides. O primeiro mecanismo, representado pela ascensão diapírica por diferença de densidade, está restrita a níveis crustais bastante dúcteis, raramente propiciando a colocação de corpos granitóides a profundidades inferiores a $10 \mathrm{~km}$ (Marsh 1982, Castro 1987). A propagação por diques (dike propagatiori) é um mecanismo que permite o desenvolvimento de falhas tensionais a mais de $40 \mathrm{~km}$ de profundidade, tendo em vista que, na presença de uma fase fluida intersticial, sob elevadas pressões, as rochas se comportam como materiais quebradiços mesmo a grandes profundidades (Shaw 1980). O desenvolvimento das falhas tensionais profundas resulta de esforços regionais e frequentemente tais falhas tensionais (e estruturas pull-aparf) associam-se a zonas de falhas transcorrentes, propiciando a colocação de magmas em níveis crustais bastante rasos (Hutton 1982, Guineberteau et ai 1987).

O estudo da origem e evolução de magmas granitóides é de extrema complexidade. Na análise desses processos, deve ser considerado inicialmente o protólito fonte e os processos magmatogênicos, bem como os de coleta e maturação magmática, profunda. Subsequentemente, devem ser consideradas as modificações impostas durante a fase de trânsito magmático e durante a fase de residência em câmaras magmáticas coletoras mais ou menos rasas. Finalmente, ainda devem ser analisadas as mudanças que ocorrem durante a cristalização magmática final e na fase subsequente, em estado subsólido (Middlemost \& Romey 1968). Neste esquema, o mecanismo de ascensão magmática é de grande importância.

Numa ascensão diapírica, os diferentes impulsos magmáticos que constituem um complexo polidiapírico representam sistemas mais ou menos fechados (Ramberg 1981), que retraiam, na sequência temporal, com maior ou menor fidelidade, a variação nos processos magmatogênicos e evolutivos na área fonte. $\mathrm{Na}$ ascensão por propagação de diques, que implica na maioria das vezes na existência de uma fase de residência do magma em câmaras coletoras mais ou menos rasas (Sibbet 1988), devem ser considerados também os processos de modificações do magma original na fase de residência. Estes incluem, entre outros, fracionamento e estratificação magmática por fenómenos de

\footnotetext{
* Departamento de Petrologia e Metalogenia, Instituto de Geociências e Ciências Exatas, Universidade Estadual Paulista, Caixa Postal 178, CEP 13506-900, Rio Claro, São Paulo, Brasil, Fax (0194) 249644

** Mineralogisch-Petrographisches Institui, Christian-Albrechts Universitat, Ludewig-Meyn Strasse 10, W-24098 Kiel 1, Alemanha

*** Instituto Geológico, Secretaria do Meio Ambiente, Avenida Miguel Stéfano, 3900, CEP 04301-903, São Paulo, São Paulo, Brasil

**** Curso de Pós-Graduação em Geociências, Instituto de Geociências e Ciências Exatas, Universidade Estadual Paulista, a/c DPM/IGCE/UNESP, Caixa

Postal 178, CEP 13506-900, Rio Claro, São Paulo, Brasil, Fax (0194) 249644
} 
múltipla difusão em bases termo-químico-gravitacionais e por efeito Soret, além das modificações por misturas magmáticas ligadas tanto ao recarregamento sucessivo da câmara magmática coletora quanto pela inversão de câmaras estratificadas por instabilidade gravitacional (Hildreth 1981, Baley et al 1976, Walkers \& Delong 1982, Martin et al 1987, Campbell \& Turner 1986, Eichelberger 1980, Rice 1985).

Por outro lado, é conhecida há longa data a vinculação entre tectônica e magmatismo (Sheinmann 1971). A combinação entre as modificações ocorridas na fase de residência magmática e a colocação de impulsos magmáticos sucessivos como respostas a sucessivas fases tectônicas é a provável causa da ocorrência de ciclos magmáticos em complexos granitóides múltiplos e compostos vinculados a expressivas, persistentes e seguidamente reativadas zonas de fraqueza crustal (Bussel \& Pitcher 1985). No Estado de São Paulo, a presença de ciclos magmáticos foi descrita detalhadamente no Complexo Granitóide Itaqui, considerando-se elementos maiores (Wernick et al 1993a) e elementos de terras raras (Wernick et al 1993c). Neste trabalho, os autores tentam mostrar a existência de ciclos magmáticos em outros complexos granitóides vinculados a expressivas falhas transcorrentes no Estado de São Paulo e, assim, ressaltar a importância do exame dos processos evolutivos que atuaram na fase de residência magmática.

\section{OBJETOS DE ESTUDO - DADOS E DEFINIÇÕES}

São considerados neste trabalho dados referentes aos Complexos Granitóides Itaqui, São Roque, Cantareira, Sorocaba, São Francisco e Itu (Intrusão Cabreúva), os três primeiros cálcio-alcalinos e os demais granitos rapakivi. Estes complexos, do Ciclo Brasiliano, associam-se com o possante feixe de falhas transcorrentes que corta o embasamento cristalino do Estado de São Paulo (Fig. 1), e cuja origem está ligada à colisão oblíqua entre as placas São Francisco e Paraná (Soares et al 1990, Wernick 1990). As falhas têm longa história evolutiva, com numerosos períodos de reativações que deformam, seccionam e deslocam os complexos a eles associados. Desta maneira, os corpos aqui considerados são em sua maior parte alongados e apresentam expressivos contatos tectônicos e importantes deslocamentos tectônicos internos.

Os dados geológicos, petrográficos e químicos utilizados estão detalhados nas bibliografias citadas e sofreram apenas um re-exame comparativo. A documentação básica é representada por dissertações e teses, executadas ou orientadas pelos autores (Godoy 1989, Ferreira 1991, Galembeck 1991, Andrade 1993), que abordam os complexos granitóides aqui considerados, acrescida da literatura secundária, de cunho mais interpretativo, derivadas das mesmas. Adicionalmente, são utilizados os dados de Dantas (1990) e de Wernick et al (1985) para o Complexo Cantareira. O grande volume de ciados disponíveis obrigou a uma extrema compactação dos mesmos e sua-restrição apenas aos aspectos mais relevantes da problemática aqui abordada.

Neste trabalho, o conceito de ciclo magmático é tomado próximo ao sentido de super-unit, de Pitcher (1985). Um ciclo é integrado por um conjunto de unidades magmáticas consanguíneas (suíte magmática), que apresentam estreitas relações espaciais e temporais. Cada unidade (ou fácies, num mapa de fácies magmáticas) do ciclo é caracterizada por feições mineralógicas, petrográficas, texturais e químicas específicas e corresponde a um impulso magmático simples. A existência de vários ciclos magmáticos implica na geração de complexos múltiplos e compostos. Denomina-se de fase magmática a um conjunto de unidades cuja colocação ocorreu sob condições tectônicas peculiares, que se retratam por tipos de jazimentos específicos (por exemplo, fase magmática de diques tardios). Um complexo múlti-

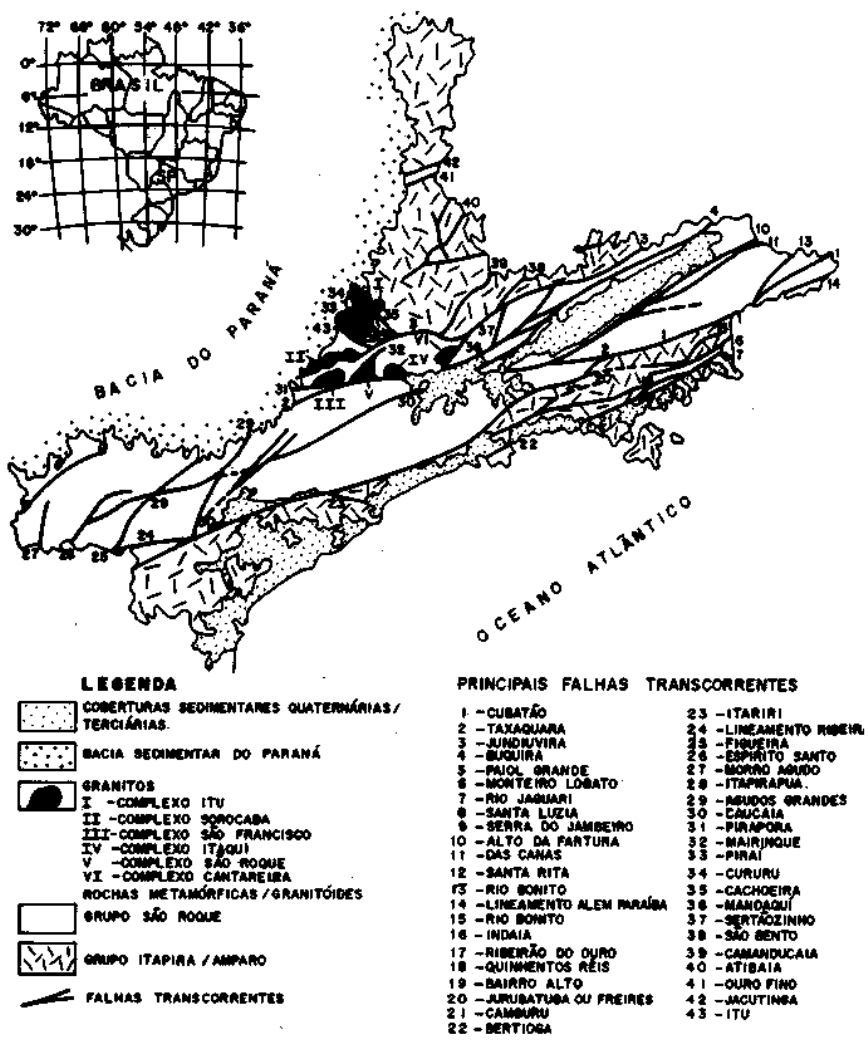

Figura 1 - Localização dos Complexos Itu, Sorocaba, São Francisco, Itaqui, São Roque e Cantareira no contexto das principais falhas transcorrentes do Estado de São Paulo Figure 1 - Location of the Itu, Sorocaba, São Francisco, Itaqui, São Roque e Cantareira Granitoid Complexes in relation to the main transcurrent faults in the State of São Paulo, Brazil

pio e composto se desenvolve pela coalescência de sucessivos impulsos magmáticos (ou unidades magmáticas) reunidos em fases magmáticas, que retratam a evolução tectônica do complexo, e em um ou mais ciclos magmáticos.

UNIDADES (FÁCIES) E FASES MAGMÁTICAS EM COMPLEXOS GRANITÓIDES ASSOCIADOS A ZONAS DE CISALHAMENTO Complexo Itaqui É um corpo cálcio-alcalino com forma de gota alongada e área de cerca de $120 \mathrm{~km}^{2}$, intrusivo em metamorfitos de baixo grau do Grupo São Roque. Associa-se à expressiva Falha Transcorrente Taxaquara que afeta o complexo, constituindo seu limite sul. O complexo mostra-se em parte afetado pela fase de dobramento regional $\mathrm{D}_{3}$, a última das três fases regionais que afetaram o Grupo São Roque (Ferreira 1991). As rochas filíticas junto aos contatos intrusivos apresentam recristalização pouco marcante, com o desenvolvimento de raras palhetas maiores de muscovita.

A arquitetura do complexo é dada por nove fácies magmáticas $\left(\mathrm{F}, \quad-\mathrm{F}_{9}\right)$, compreendendo principalmente granodioritos e monzogranitos, ao lado de diques mais máficos (Ferreira \& Wernick 1991) e resulta da coalescência de cinco fases magmáticas (Wernick \& Ferreira 1993): 1. uma fase de intrusões forçadas, compreendendo as fácies $F_{t}$ e $F_{2} ; 2$. uma fase de colocação de espessos corpos subtabulares verticais dada pela fácies $\mathrm{F}_{3} ; 3$. uma fase de diques mais máficos e mais rasos em relação aos precedentes, que reúne as fácies $\mathrm{F}_{4}$ e $\mathrm{F}_{5} ; 4$ 4 uma fase de colocação de stocks rasos e de um dique anelar dado pelas fácies $\mathrm{F}_{6}, \mathrm{~F}_{7}$, e $\mathrm{F}_{8}$ 5. uma fase de diques terminais com turmalina $\mathrm{e}$ muscovita dada, pela fácies $\mathrm{F}_{9}$. 
Para os objetivos deste trabalho, as fases $1,2,4$ e 5 foram redenominadas, respectivamente, de fase principal, de acresção lateral inicial, de stocks e bossas, mantendo-se a designação de fases dos diques máficos para a fase $\mathrm{F}_{3}$. A figura 2 mostra a arquitetura simplificada do Complexo Itaqui e a figura 3 algumas composições modais de suas unidades magmáticas, reunidas em fases magmáticas. Na figura 4 consta a variação química das nove unidades magmáticas do complexo e as figuras 7 a 10 expressam as relações $\left(\mathrm{Na}_{2} \mathrm{O}+\mathrm{K}_{2} \mathrm{O}\right)$ x $\mathrm{SiO}_{2}, \mathrm{~K}_{2} \mathrm{O}$ × $\mathrm{Na}_{2} \mathrm{O}, \mathrm{K} / \mathrm{Rb}$ x $\mathrm{SiO}_{2}$ e $\mathrm{Rb}$ x $\mathrm{Sr}$, das diversas fases magmáticas.

Complexo São Roque É um corpo cálcio-alcalino, com área de cerca de $190 \mathrm{~km}^{2}$, forma grosseiramente triangular e contatos eminentemente tectônicos. Encontra-se embutido em metamorfitos de baixo grau do Grupo São Roque e vinculado à falha transcorrente Taxaquara que constitui seu contato sul (Andrade et al. 1992). Fenómenos de metamorfismo de contato são discretos, restritos nos filitos ao desenvolvimento de palhetas maiores de muscovita. Em rochas calcárias, presentes sob formas de enclaves e tetos pendentes no complexo, os fenómenos termometamórficos são mais patentes, chegando ao desenvolvimento de diopsídio (Andrade 1993). A sua arquitetura é dada por nove fácies magmáticas $\left(\mathrm{F}_{\mathrm{t}}-\mathrm{F}_{9}\right)$, que compreendem principalmente granodioritos e monzogranitos ao lado de diques mais máficos, e resulta da coalescência de quatro fases magmáticas: 1. uma fase de intrusões forçadas reunindo as fácies $\mathrm{F}$ ! e $\mathrm{F}_{2} ; 2$. uma fase de stocks e bossas de colocação cada vez mais rasa, iniciando com rochas cálcio-alcalinas das fácies $\mathrm{F}_{3}, \mathrm{~F}_{5}$, e $\mathrm{F}_{6} \mathrm{e}$ terminando com turmalina (muscovita) granitos das fácies $\mathrm{F}_{7}$ e $\mathrm{F}_{8} ; 3$. uma fase de colocação de diques mais máficos dado pela fácies $\mathrm{F}_{4}$; 4 . uma fase de colocação de diques terminais portadores, ou não, de turmalina, representada pela fácies $\mathrm{F}_{9}$ (Andrade 1993).

Desta maneira, o Complexo São Roque tem uma história de colocação magmática muito semelhante à do Complexo Itaqui, faltando apenas a fase de acresção lateral inicial. Semelhança existe também nas litologias (domínio de granodioritos e monzogranitos), inclusive com a presença de turmalina nos aplitos tardios. A figura 2 mostra a arquitetura simplificada do Complexo São Roque e a figura 3 algumas composições modais de suas unidades magmáticas reunidas em fases magmáticas. Na figura 4 consta a variação química das nove unidades magmáticas do complexo e as figuras 7 a 10 expressam as relações $\left(\mathrm{Na}_{2} \mathrm{O}+\mathrm{K}_{2} \mathrm{O}\right)$ x $\mathrm{SiO}_{2}, \mathrm{~K}_{2} \mathrm{O}$ x $\mathrm{Na}_{2} \mathrm{O}$, $\mathrm{K} / \mathrm{Rb} \times \mathrm{SiO}_{2}$ e $\mathrm{Rb}$ x Sr das fases magmáticas.

Complexo Cantareira É um corpo com fornia de gota espessada para SW, eixo maior segundo a direção N30E, área de cerca de $320 \mathrm{~km}^{2}$ e associado com a Falha Transcorrente Mandaqui que delimita, junto com as Falhas Barro Branco e Cabuçu, a maior parte do seu contato oriental. Segundo Dantas (1990), trata-se de complexo sin a tardi-tectônico intrusivo em metamorfitos de baixo grau do Grupo São Roque, em relação aos quais desenvolve, localmente, fraco metamorfismo de contato que inclui a recristalização de filossilicatos das encaixantes, bem como sua feldspatização e turmalinização. Característica é a elevada frequência de xenólitos e tetos pendentes de rochas encaixantes, além da presença de uma constricção transversal, na altura da cidade de Perus, que subdivide o complexo geograficamente numa porção SW e outra NE. Para o qual existe um mapa faciológico detalhado, em
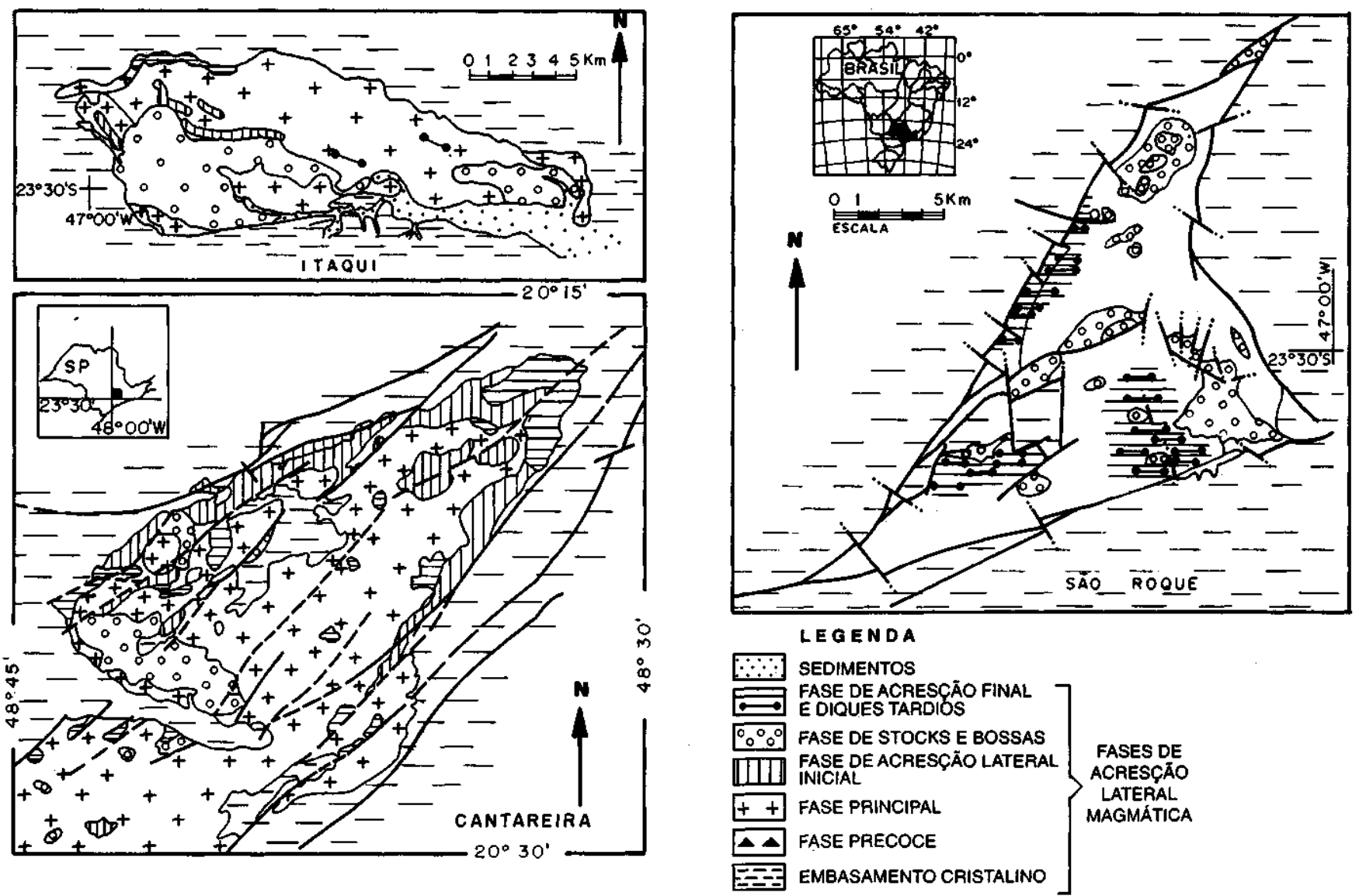

Figura 2 -Arquitetura dos Complexos Granitóides Itaqui, São Roque e Cantareira sobre suas fases magmáticas constituintes Figure 2 - Architecture of the Itaqui, São Roque and Cantareira Granitoid Complexes in terms of their upbuilding magmatic phases 

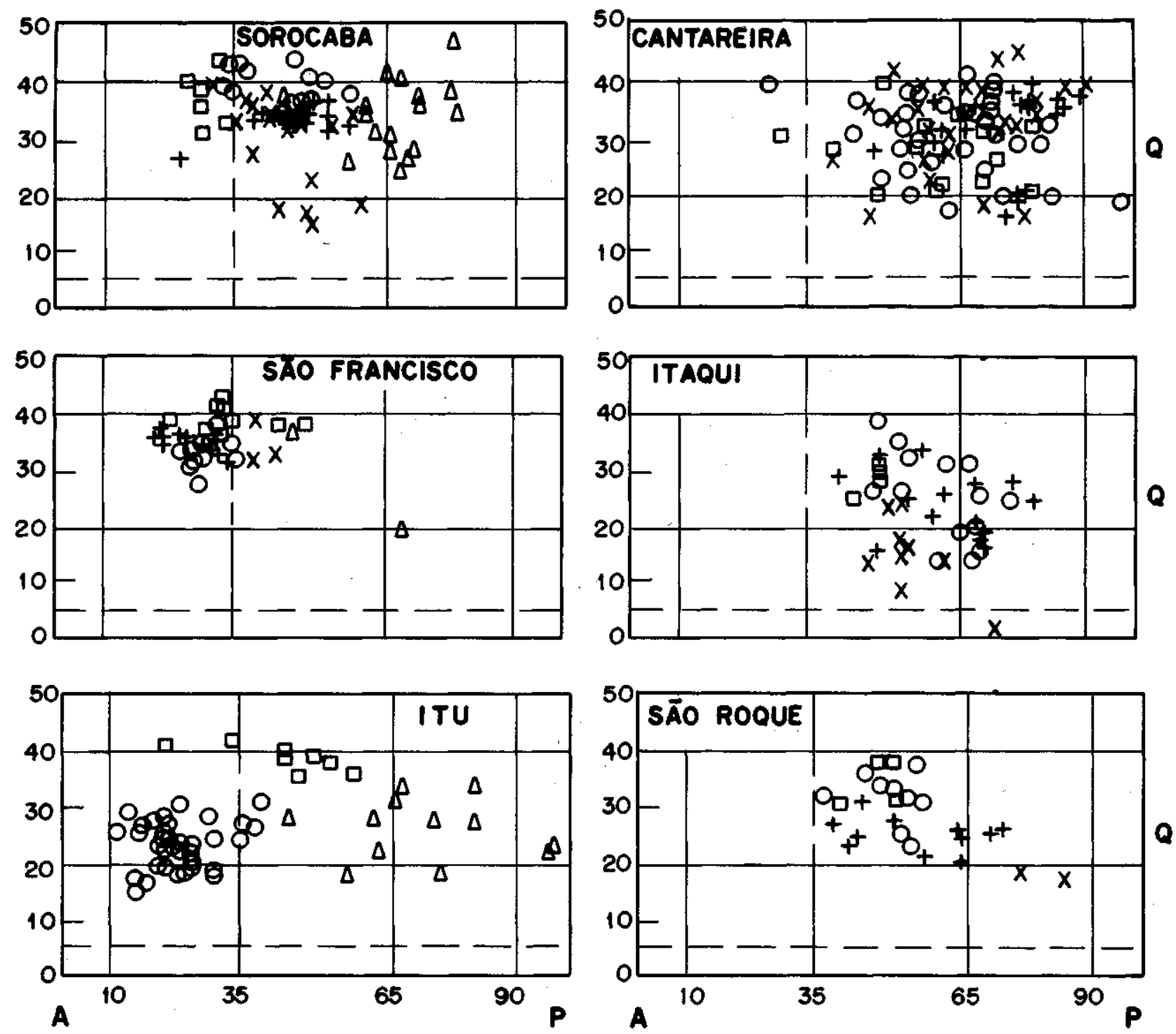

Figura 3 - Composição modal de algumas rochas das diversas unidades magmáticas (fácies magmáticas) dos Complexos Granitóides Itaqui, São Roque, Cantareira, São Francisco, Sorocaba e Itu (Intrusão Cabreúva), agrupados em fases magmáticas, em diagrama QAP retangular. Fases: precoce $(\Delta)$; principal (+); acresção lateral (X); stocks e intrusões circulares (O); acresção final ( $\square$ )

Figure 3 - Modal composition of some rocks from different magmatic units (magmatic fácies) from the Itaqui, São Roque, Cantareira, São Francisco, Sorocaba and Itu (Cabreúva intrusion) granitoid complexes, assembled in magmatic phases, in a retangular QAP diagram. Phases:. early (A); main (+); lateral accretion $(\mathrm{X})$; stocks and circular intrusions $(\bigcirc)$; final accretion $(\square)$

conjugação com estudos petrográficos e geoquímicos (Dantas 1990), que detalham consideravelmente os trabalhos de Rego (1937), Rego \& Santos (1938) è Wernick et al. (1985).

A semelhança dos Complexos Itaqui e São Roque, o Granitóide Cantareira é constituído dominantemente por granodioritos e monzogranitos porfiróides, portadores ou não de pequenas quantidades de hornblenda. Segundo Wernick et al. (1985), baseado na tipologia de zircão, tratase de corpo com características transicionais entre granitos crustais profundos e cálcio-alcalinos, na classificação de Pupin (1980).

A arquitetura da porção NE do complexo, com área de aproximadamente $230 \mathrm{~km}^{2}$, compreende oito fácies $\left(\mathbf{F}_{\mathbf{1}}-\mathbf{F}_{\mathbf{8}}\right)$, designadas por Dantas (1990) de: $\mathbf{F}_{\mathbf{1}}$ - Pirituba; $\mathbf{F}_{2}$ Itaguassu; $\mathbf{F}_{3}$ - Canivete; $\mathbf{F}_{4}$ - Petrópolis; $\mathbf{F}_{5}$ - Mandaqui; $\mathbf{F}_{6}$ Tremembé; $\mathbf{F}_{7}$ - Hortolândia; e $\mathbf{F}_{\mathbf{8}}-$ Santa Inês, e resulta da coalescência de 5 fases magmáticas: 1. uma fase principal representada pela fácies $F_{1} \mathbf{2}$. uma fase de acresção lateral inicial, que reúne as fácies $\mathrm{F}_{2}$ e $\mathrm{F}_{3} ; 3$. uma fase de intrusão de stocks e bossas dada pelas fácies $\mathrm{F}_{4} \mathrm{e}_{5} ; 4$. uma fase de acresção final, que reúne as fácies $\mathrm{F}_{6}, \mathrm{~F}_{7} \mathrm{e} \mathrm{F}_{\mathrm{g}}$.

Desta maneira, o Complexo Cantareira tem uma história de colocação magmática muito semelhante a dos Complexos Itaqui e São Roque, faltando apenas a fase dos diques máficos. Entretanto, rochas que podem ser referidas a esta fase ocorrem sob forma de enclaves, cuja forma e disposição espacial é a de diques sin-plutônicos disruptos (Wernick 1983, Dantas 1990). Semelhança existe também ao nível das litologias, dadas dominantemente por granodioritos e monzogranitos, inclusive com a presença de turmalina nos diques tardios. A figura 2 mostra a arquitetura simplificada do Complexo Cantareira e a figura 3 algumas composições modais de suas unidades magmáticas (extraídas de Dantas 1990), reunidas em fases magmáticas. Na figura 4 , consta a variação química das oito unidades magmáticas do complexo e as figuras 7 a 10 expressam as relações $\left(\mathrm{Na}_{2} \mathrm{O}+\mathrm{K}_{2} \mathrm{O}\right) \mathrm{x}$ $\mathrm{SiO}_{2}, \mathrm{~K}_{2} \mathrm{O} \times \mathrm{Na}_{2} \mathrm{O}, \mathrm{K} / \mathrm{Rb} \times \mathrm{SiO}_{2}$ e $\mathrm{Rb} \times \mathrm{Sr}$ das diversas fases 

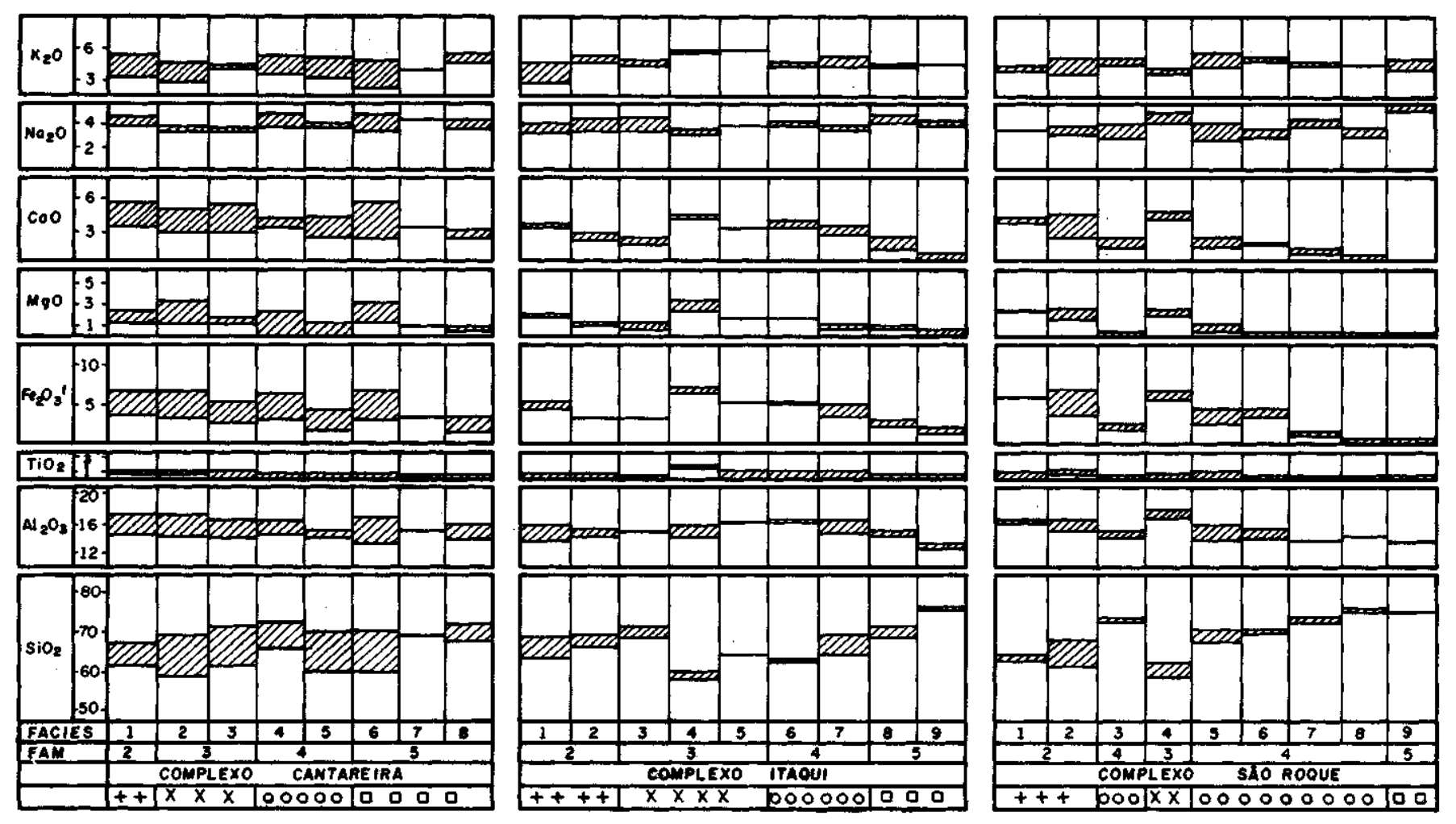

Figura 4 - Variabilidade química (elementos maiores) das unidades magmáticas (fácies) dos Complexos Granitóides Itaqui, São Roque e Cantareira, agrupados por fases de acresção magmática (FAM). Fases: principal (+); acresção lateral (X); stocks e intrusões circulares (O); acreş̧ão final ( $\square$ )

Figure 4- Chemical variability (major elements) of the magmatic units (Fácies) from the Itaqui, São Roque and Cantareira Granitoid Complexes, assembled in magmatic accretion phases (FAM). Phases: main (+); lateral accretion (X); stocks and circular intrusions (o); final accretion ( $\square$ )

magmáticas, baseadas em dados de Wernick et al. (1985) e Dantas (1990).

Complexo São Francisco É um complexo rapakivi com forma de gota e área de $150 \mathrm{~km}^{2}$, intrusivo nos metamorfitos de baixo grau do Grupo São Roque, nos quais origina distinta auréola de contato. Vincula-se às Falhas Transcorrentes Taxaquara e Pirapora, que determinam parte dos seus contatos. Sua disposição geral segue os eixos das estruturas sinformais e antiformais ligados à fase de dobramento $\mathrm{D}_{3}$ (Godoy 1989).

Sua arquitetura compreende oito fácies $\left(\mathrm{F},-\mathrm{F}_{\mathrm{g}}\right)$, dadas principalmente por sienogranitos e, subordinadamente, monzogranitos (Godoy \& Figueiredo 1991a) e resulta da coalescềncia de quatro fases magmáticas (Godoy \& Wernick 1992a, Wernick et al. 1993b): 1. uma fase precoce dada por quartzo monzodioritos $\left(\mathrm{F}_{1}\right) ; 2$. uma fase principal dada pelos sienogranitos da unidade magmática $\mathrm{F}_{2} ; 3$. uma fase de crescimento lateral representada pela fácies $\mathrm{F}_{3} ; 4$. uma fase de colocação de stocks compreendendo as fácies $\mathrm{F}_{4} \mathrm{e} \mathrm{F}_{5} ; \mathbf{5}$. uma fase final de crescimento lateral e de colocação de diques tardios dados pelas fácies $\mathrm{F}_{6}, \mathrm{~F}_{7}$ e $\mathrm{F}_{8}$. Pairam dúvidas sobre a real posição temporal da fácies $F_{1}$ que ocorre sob forma de enclaves e megaenclaves nas fácies $\mathrm{F}_{2} \mathrm{e} \mathrm{F}_{3}$. A fácies $\mathrm{F}$, pode representar tanto, como aqui considerado, um estágio precoce da fase intrusiva principal quanto diques sinplutônicos, despedaçados e intrusivos entre as fácies magmáticas $\mathrm{F}_{3}$ e $\mathrm{F}_{4}$, à semelhança dos Complexos Itaqui e São Roque.

Desta maneira, o Complexo São Francisco tem a mesma história de colocação magmática dos complexos cálcio-alcalinos previamente descritos e também vinculados com ex- pressivas falhas transcorrentes. A figura 5 mostra a arquitetura simplificada do Complexo São Francisco e a figura 3 algumas composições modais de suas unidades magmáticas reunidas em fases magmáticas. Na figura 6 consta a variação química das oito unidades magmáticas do complexo e as figuras 7 a 10 expressam relaçồes $\left(\mathrm{Na}_{2} \mathrm{O}+\mathrm{K}_{2} \mathrm{O}\right) \mathrm{x}$ $\mathrm{SiO}_{2}, \mathrm{~K}_{2} \mathrm{O} \times \mathrm{Na}_{2} \mathrm{O}, \mathrm{K} / \mathrm{Rb} \times \mathrm{SiO}_{2}$ e $\mathrm{Rb}$ x $\mathrm{Sr}$ das diversas fases magmáticas.

Complexo Sorocaba Trata-se de um granito rapakivi com forma sigmoidal e área de $180 \mathrm{~km}^{2}$ - intrusivo em metamorfitos de baixo grau do Grupo São Roque, em relação aos quais desenvolve localmente distinta auréola de contato. Sua colocação é controlada pela continuidade da Falha Transcorrente Jundiuvira e apresenta posicionamento tardi a pós $\mathrm{D}_{3}$ (Godoy 1989 ).

O complexo foi seccionado por duas falhas normais transversais originando três segmentos que foram alçados diferencialmente em forma de escada, de tal modo que o segmento menos soerguido corresponde ao topo da intrusão, ainda contendo tetos pendentes das rochas encaixantes, e o mais alçado a níveis mais profundos.

Sua arquitetura compreende 18 fácies $\left(\mathrm{F},-\mathrm{F}_{18}\right)$, dadas por dioritos, granodioritos, monzogranitos e sienogranitos (Godoy \& Figueiredo 1991 b) e resulta da coalescência de cinco fases magmáticas (Godoy \& Wernick 1992b, Wernick et al. 1993b): 1. uma fase precoce reunindo as fácies $F, F_{2}$ $\mathrm{e}_{3} ; 2$. uma fase principal, inferior, dada pela fácies $\mathrm{F}_{4}$, que corresponde à maior parte do segmento mais alçado e engloba rochas da fase anterior; 3. uma fase principal, superior, dada pelas fácies $\mathrm{F}_{5} \mathrm{e} \mathrm{F}_{6}$ e que constitui a maior parte do 

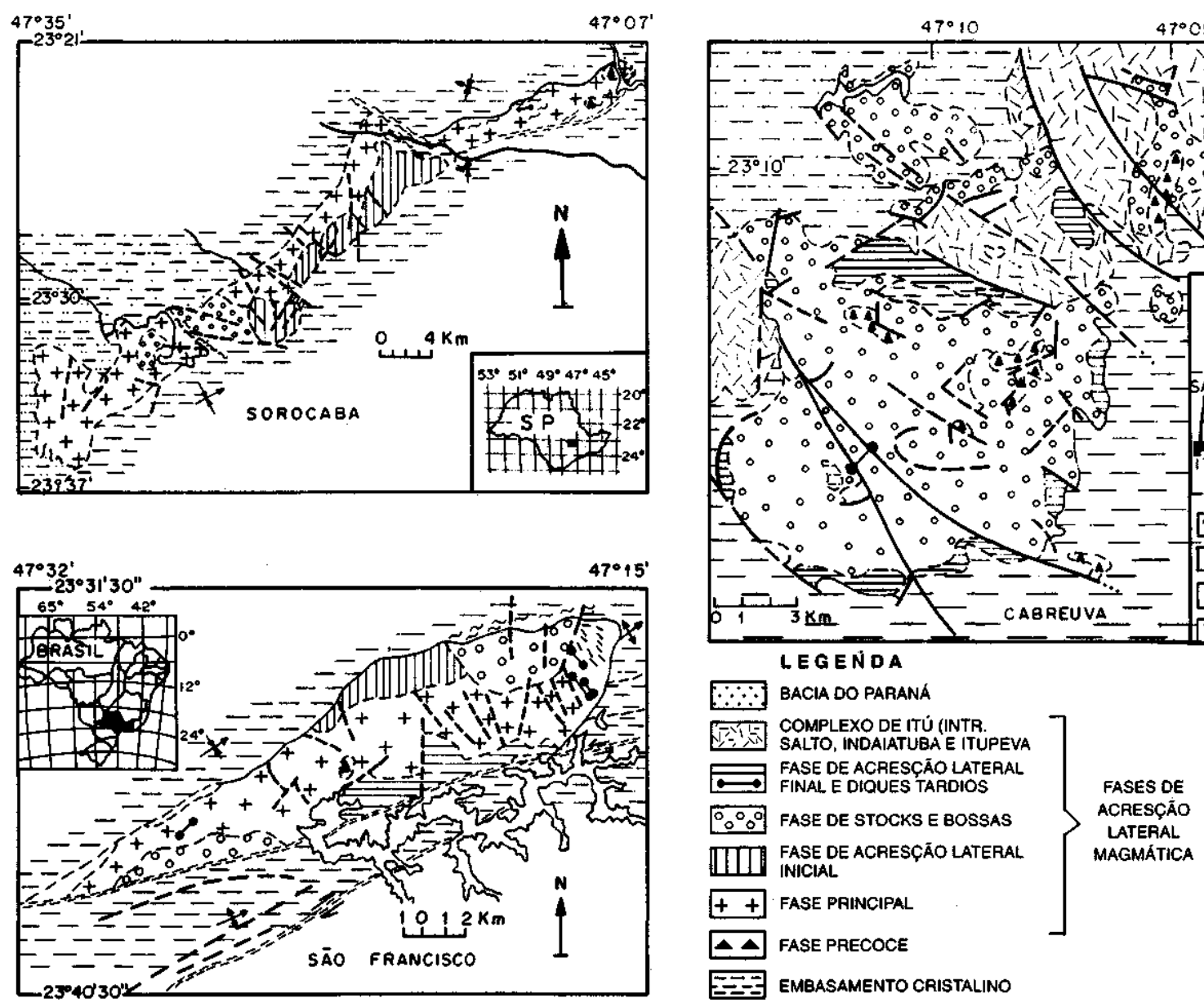

Figura 5-Arquitetura dos Complexos Rapakivi São Francisco, Sorocaba e Itu (Intrusão Cabreíva), em termos de suas fases magmâticas constituintes

Figure 5 - Architecture of the São Francisco, Sorocaba e Itu (Cabreúva Intrusion) rapakivi complexes in terms of their upbuilding magmatic phases

segmento menos soerguido; 4. uma fase de colocação de stocks e bossas dispostos paralelamente à borda longitudinal do segmento central, dada pelas fácies $\mathrm{F}_{7}$ a $\mathrm{F}_{11} ; \mathbf{5}$. uma fase de colocação de stocks e bossas paralelamente à direção das falhas transversais,que seccionam o complexo e que reúne as fácies $\mathrm{F}_{12}$ a $\mathrm{F}_{15} ; \mathbf{6}$. uma fase de intrusão de pequenos corpos equigranulares, aplitos e pegmatitos finais, dada pelas fácies $\mathrm{F}_{16} \mathrm{a} \mathrm{Fi}_{8}$.

Dessa maneira, o Complexo Sorocaba apresenta a mesma história de colocação magmática do Complexo São Francisco, apesar de sua estruturação mais complexa devido aos soerguimentos diferenciais dos seus diversos segmentos ao longo das falhas normais transversais. Igualmente, pairam dúvidas sobre a real situação temporal da unidade magmática $F_{1}$ (que ocorre sob forma de enclaves com dimensões variáveis na unidade $\mathrm{F}_{4}$ ) podendo corresponder tanto, como aqui considerado, à uma fase magmática precoce quanto a diques máficos sin-plutônicos desmembrados. As grandes dimensões dos enclaves, até métricos, não é argumento que possa descartar a segunda hipótese, face as grandes espessuras dos diques máficos, até decamétricas, presentes no Complexo Itaqui (Wernick \& Ferreira 1987). A figura 5 mostra a arquitetura simplificada do Complexo Sorocaba e a figura 3 algumas composições modais de suas unidades magmâticas reunidas em fases magmâticas. Na figura 6 consta a variação química das 18 unidades magmấticas do complexo e as figuras 7 a 10 expressam relações $\left(\mathrm{Na}_{2} \mathrm{O}+\mathrm{K}_{2} \mathrm{O}\right)$ x $\mathrm{SiO}_{2}$, $\mathrm{K}_{2} \mathrm{O} \times \mathrm{Na}_{2} \mathrm{O}, \mathrm{K} / \mathrm{Rb} \times \mathrm{SiO}_{2}$ e $\mathrm{Rb} \times \mathrm{Sr}$, das diversas fases magmâticas.
Complexo Itu $E^{E}$ um complexo rapakivi constituído pela coalescência de quatro intrusões subcirculares a irregulares (Intrusões Salto, Indaiatuba, Itupeva e Cabreúva), com uma área total de $310 \mathrm{~km}^{2}$. E intrusivo em metamorfitos de médio/alto grau dos Grupos Amparo e Itapira e associa-se à Falha Transcorrente Itu, uma ramificação da Falha Jundiuvira. O complexo é seccionado por várias falhas transcorrentes menores, que resultam do splitting offda Falha Itu (Galembeck 1991). A maior das intrusões, a Cabreúva, tem área de $160 \mathrm{~km}^{2}$ e sua arquitetura compreende seis fácies $\left(\mathrm{F},-\mathrm{F}_{6}\right)$ dadas, principalmente, por quartzo sienitos e sienogranitos e, subordinadamente, por tonalitos, granodioritos, quartzo monzonitos e monzogranitos (Galembeck et al. 1991).

A intrusão Cabreúva resulta da coalescência de três fases magmâticas (Wernick et al 1993b): 1. uma fase precoce dada pela associação de fácies $\mathrm{Fj}$ que reúne tonalitos, granodioritos e quartzo monzonitos, cáicio-alcalinos, ao lado de granodioritos $\left(\mathrm{F}_{2}\right)$ e quartzo monzonitos-monzogranitos $\left(\mathrm{F}_{3}\right)$, subalcalinos potássicos; 2 . uma fase de intrusã̃o de quartzo sienitos/sienogranitos $\left(\mathrm{F}_{4}\right)$, que constitui o grosso da estrutura circular. As rochas da fase magmática precoce ocorrem como mega-enclaves na fase magmática $2 ; 3$. uma fase de colocação de um dique anelar e de pequenas intrusões ao longo de falhas, além de diques terminais, dada pela fácies $\mathrm{F}_{5}$ e $\mathrm{F}_{6}$. AF fácies $\mathrm{F}_{4}, \mathrm{~F}_{5}$ e $\mathrm{F}_{6}$ são rochas com tendências alcalinas (Wemic' et al 1991,Paschoalattieí0/. 1987).

A segunda fase magmática, que origina o grosso da intrusão centrada Cabreúva, pode ser correlacionada com a fase de colocação de bossas, stocks e intrusões circulares presentes nos Complexos Cantareira, Itaqui, São Roque, São 

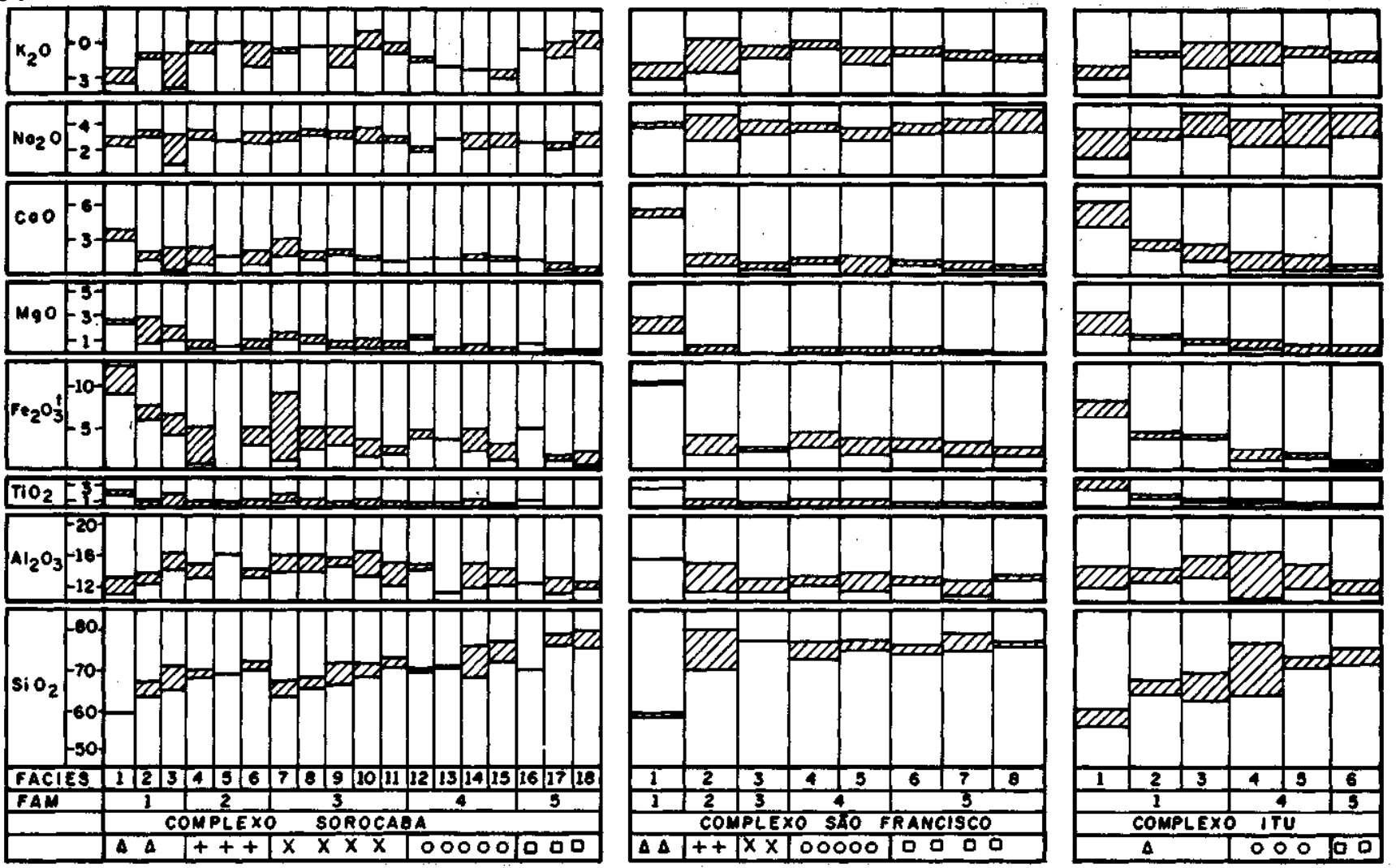

Figura 6 - Variabilidade química (elementos maiores) das unidades magmáticas (fácies) dos Complexos Rapakivi São Francisco, Sorocaba e Itu (Intrusão Cabreúva), agrupados por fases de acresção magmáticas (FAM). Fases: precoce (A); principal (+); acresção lateral (X); stocks e intrusões circulares (O); acresção final ( $\square$ )

Figure 6- Chemical variability (major elements) of the magmatic units (Fácies) from São Francisco, Sorocaba e Itu (Cabreúva Intrusion) rapakivi complexes, assembled in magmatic accretion phases (FAM). Phases: early $(\Delta)$; main (+); lateral accretion (X); stocks and circular intrusions (o); final accretion ( $\square$ )

Francisco e Sorocaba. Em todos os seis complexos aqui considerados, estas intrusões são seccionadas pela última grande fase de reativação das falhas transcorrentes, às quais se vinculam. Quanto a fase magmática precoce, ela reúne dois tipos de litologias: rochas cálcio-alcalinas $(\mathrm{F}$,$) e rochas$ subalcalinas potássicas $\left(\mathrm{F}_{2}\right.$ e $\left.\mathrm{F}_{3}\right)$, ambas presentes apenas sob forma de enclaves e mega-enclaves, até quilométricos, presentes na unidade $\mathrm{F}_{4}$. Enquanto as unidades $\mathrm{F}_{2}$ e $\mathrm{F}_{3}$ estão diretamente vinculadas com a Intrusão Cabreúva, a unidade $\mathrm{F}$, representa enclaves de um magmatismo cálcio-alcalino precedente, ao qual o magmatismo rapakivi foi espacialmente superimposto, à semelhança da Intrusão Rapakivi Sguario (Rothmaier 1994). A figura 2 mostra a arquitetura simplificada da Intrusão Cabreuva e a figura 3 algumas composições modais de suas unidades magmáticas reunidas em fases magmáticas. Na figura 6 consta a variação química das seis unidades magmaticas do complexo e as figuras 7 a 10 expressam relações $\left(\mathrm{Na}_{2} \mathrm{O}+\mathrm{K}_{2} \mathrm{O}\right)$ x $\mathrm{SiO}_{2}, \mathrm{~K}_{2} \mathrm{O}$ x $\mathrm{Na}_{2} \mathrm{O}, \mathrm{K} / \mathrm{Rb}$ x $\mathrm{SiO}_{2}$ e $\mathrm{Rb}$ x $\mathrm{Sr}$ das diversas fases magmáticas.

SEQÜENCIAÇÃO TEMPORAL DE FASES MAGMÁTICAS A prévia descrição da arquitetura de três complexos cálcio-alcalinos (Itaqui, São Roque, Cantareira) e três complexos rapakivi (São Francisco, Sorocaba, Itu), todos associados com expressivas zonas de cisalhamento ou suas ramificações, mostra a existência de uma mesma evolução em termos da natureza e da sucessão temporal de suas fases magmáticas constituintes, se bem que, uma ou mais destas fases possam faltar em certos complexos específicos.

Esta evolução é dada por uma fase inicial ou precoce cujo registro se faz apenas por meio de enclaves e mega-enclaves presentes nas unidades magmáticas das fases mais jovens. Segue-se a fase magmática principal, caracterizada por uni- dades magmáticas muito ricas em estruturas de fluxo, expressas por leitos alternadamente enriquecidos e empobrecidos em megacristais de feldspato, megacristais dispostos em estruturas "espiga de milho", concentrações coalescentes de megacristais aos quais se associam leitos e schlieren marginais empobrecidos ou desprovidos de megacristais, megacristais isorientados, megacristais de feldspato coalescentes em forma de "asa de andorinha", megacristais arqueados, enclaves fusiformes e isorientados, schlieren com disposição paralela ou subparalela etc.

Estas estruturas, conjuntamente com a posição espacial da fase principal, sugere que a colocação das unidades magmáticas ocorrem sob condições forçadas em espaços tipo pull apart, gerados ao longo das falhas transcorrentes e marcam, assim, uma fase importante de sua movimentação. Segue uma fase de acresção lateral, com a colocação de novas massas magmáticas tanto sob a forma de espessos diques precoces no interior do complexo quanto sob forma de acresções marginais em relação às unidades magmáticas, colocadas durante a fase principal. A próxima fase magmática é dada pela colocação de stocks, bossas e intrusões circulares com dimensões variadas que cortam as unidades magmáticas da fase principal. A colocação, em parte também forçada, destas intrusões se manifestam por meio de estruturas de fluxo subverticais presentes, por exemplo, nas bossas do Complexo Itaqui (Ferreira, em preparação). A história magmática se encerra com uma fase de acresção final, durante a qual ocorre a colocação de diques, pequenas intrusões ao longo de falhas secundárias, diques anelares ou de massas irregulares nas porções terminais dos complexos ovalados ou fusiformes (Figs. 2 e 5 ).

Durante a sequência de colocação das fases magmáticas são reconhecíveis pelo menos dois grandes períodos de movimentação das falhas transcorrentes, às quais se asso- 

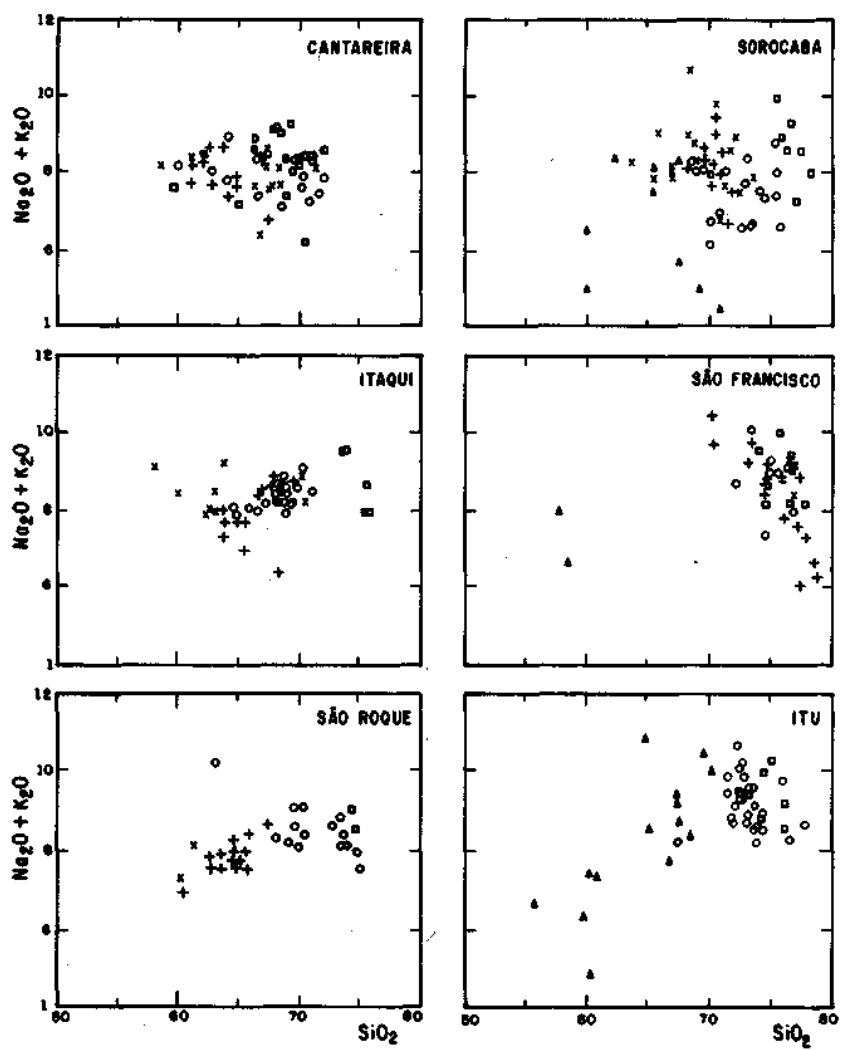

Figura 7 - Diagramas $\left(\mathrm{Na}_{2} \mathrm{O}+\mathrm{K}_{2} \mathrm{O}\right) \times \mathrm{SiO}_{2}$ (óxidos em \% de peso) para rochas das unidades magmáticas dos Complexos Granitóides Itaqui, São Roque, Cantareira, São Francisco, Sorocaba e Itu (Intrusão Cabreúva), agrupadas por fases magmáticas. Fases: precoce (4); principal (+); acresção lateral $(X)$; stocks $e$ intrusões circulares (०); acresção final ( $\square$ ) Figure $7-\left(\mathrm{Na}_{2} \mathrm{O}+\mathrm{K}_{2} \mathrm{O}\right) \times \mathrm{SiO}_{2}$ diagrams (oxides in weight \%) for rocks from magmatic units from the Itaqui, São Roque, Cantareira, São Francisco, Sorocaba e Itu (Cabreúva Intrusion) Granitoid Complexes, assembled in magmatic phases. Phases: early $(\square)$; main $(+)$; lateral accretion $(X)$; stocks and circular intrusions $(\odot)$; final accretion $(\square)$

ciam os complexos, granitóides. Ao primeiro vincula-se a geração de espaços tipo pull apart que propicia a colocação forçada das unidades magmáticas da fase principal, enquanto o segundo é posterior à colocação das unidades magmáticas da fase dos stocks, bossas e intrusões circulares, pois, estas são seccionadas e deslocadas por falhas transcorrentes. O Complexo São Francisco (Fig. 5) retrata de maneira clara esta relação.

CICLOS MAGMÁTICOS Dados químicos (elementos maiores) referentes a todas as unidades magmáticas (fácies magmáticas) dos seis complexos granitóides considerados, estão reunidos nos histogramas das figuras 4 e 6 e as relações $\left(\mathrm{NajO}+\mathrm{K}_{2} \mathrm{O}\right)$ x $\mathrm{SiO}_{2}, \mathrm{~K}_{2} \mathrm{O}$ x NaA K/Rb x $\mathrm{SiO}_{2}$ e $\mathrm{Rb} \times \mathrm{Sr}$ das fases magmáticas, nas quais são reunidas, constam nas Figuras 7, 8, 9 e 10.

Para o Complexo Itaqui, o histograma da figura 4 permite a definição de dois ciclos magmáticos. O primeiro compreende as unidades magmáticas $\mathrm{F}_{1}, \mathrm{~F}_{2}$ e $\mathrm{F}_{3}$ e o segundo as unidades $\mathrm{F}_{6}, \mathrm{~F}_{7}, \mathrm{~F}_{8}$ e $\mathrm{F}_{9}$. Os ciclos são separados pela fase magmática dos diques máficos que reúne as unidades $\mathrm{F}_{4}$ e $\mathrm{F}_{5}$, feição comum em complexos cálcio-alcalinos (Pitcher \& Bussel 1985). A caracterização detalhada destes ciclos magmáticos, enfocando elementos maiores e de terras raras, é devido a Wernick et al (1993a, c).

A mesma situação ocorre no Complexo São Roque (Figura 4), onde Andrade (1993) não considerando os granitos
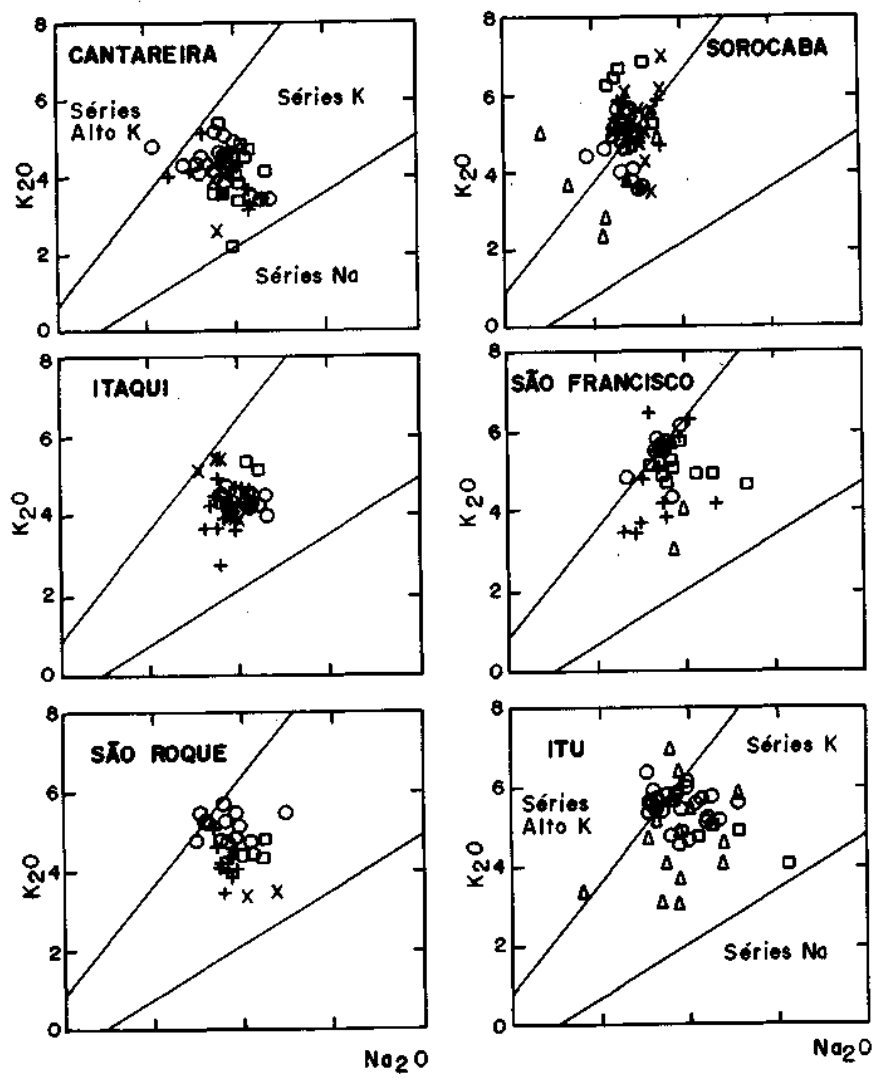

Figura 8 - Diagramas $\mathrm{Na}_{2} \mathrm{O} \times \mathrm{K}_{2} \mathrm{O}$ (óxidos em \% de peso) para rochas das unidades magmáticas dos Complexos Granitóides Itaqui, São Roque, Cantareira, São Francisco, Sorocaba e Itu (Intrusão Cabreúva), agrupadas por fases magmáticas. Fases: precoce (4); principal (+); acresção lateral $(X)$; stocks e intrusões circulares (O); acresção final ( $\square$ ) Figure $8-\mathrm{Na}_{2} \mathrm{O} \times \mathrm{K}_{2} \mathrm{O}$ diagrams (oxides in weight \%) for rocks from magmatic units from the Itaqui, São Roque, Cantareira, São Francisco, Sorocaba e Itu (Cabreúva Intrusion) Granitoid Complexes, assembled in magmatic phases. Phases: early (A); main (+); lateral accretion (X); stocks and circular intrusions (०); final accretion $(\square)$

crustais portadores de muscovita + ou - turmalina (unidades $\mathrm{F}_{7}$ e $\mathrm{F}_{8}$ ), definiu dois ciclos magmáticos cálcio-alcalinos. $\mathrm{O}$ primeiro compreende as unidades $\mathrm{F}_{15} \mathrm{~F}_{2}$ e $\mathrm{F}_{3}$ e o segundo as unidades $\mathrm{F}_{5}, \mathrm{~F}_{6}$ e $\mathrm{F}_{7}$. Também aqui os dois ciclos são separados pela fase magmática dos diques máficos, dada pela unidade $\mathrm{F}_{4}$

No Complexo Cantareira os dados (Fig. 4) sugerem, também, a existência de dois ciclos magmáticos. $\mathrm{O}$ primeiro reúne as unidades magmáticas $\mathrm{F}_{1}, \mathrm{~F}_{2}, \mathrm{~F}_{3}$ e $\mathrm{F}_{4}$ e o segundo as unidades $\mathrm{F}_{5}, \mathrm{~F}_{6}, \mathrm{~F}_{7}$ e $\mathrm{F}_{8}$. Falta a fase magmática dos diques máficos que separa os dois ciclos nos Complexos Itaqui e São Roque, se bem que a presença da mesma é sugerida por enclaves microgranulares máficos de diques sin-plutônicos disruptos (Dantas 1990).

Em relação aos ciclos magmáticos dos três complexos cálcio-alcalinos aqui considerados, cabe ainda destacar que:

- o impulso inicial do segundo ciclo pode ser tanto mais básico quanto mais ácido que o impulso magmático do ciclo inicial (Fig. 4);

- cada ciclo é constituído por unidades magmáticas quimicamente mais ou menos expandidas e que não existe uma relação entre a variabilidade química das unidades magmáticas e seu teor médio de $\mathrm{SiO}_{2}$. Tal fato indica que durante sua colocação e consolidação, os seguidos impulsos magmáticos sofreram variados graus de fracionamento; 

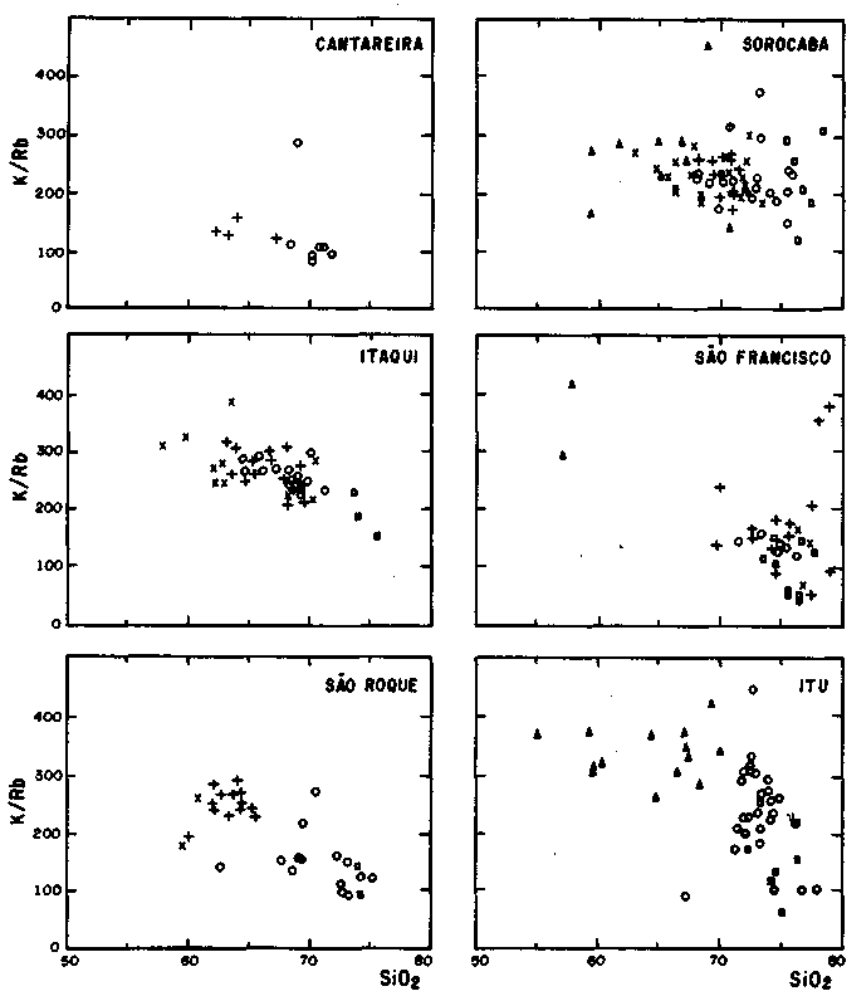

Figura 9 - Diagramas $\mathrm{K} / \mathrm{Rb} \times \mathrm{SiO}_{2}$ para rochas das unidades magmáticas dos Complexos Granitóides Itaqui, São Roque, Cantareira, São Francisco, Sorocaba e Itu (Intrusão Cabreúva), agrupados por fases magmáticas. Fases: precoce $(\Delta)$; principal (+); acresção lateral $(X)$; stocks $e$ intrusões circulares (०); acresção final (口) Figure $9-\mathrm{K} / \mathrm{Rb} \times \mathrm{SiO}_{2}$ diagrams for rocks from magmatic units from the Itaqui, São Roque, Cantareira, São Francisco, Sorocaba e Itu (Cabreúva intrusion) granitoid complexes, assembled in magmatic phases. Phases: early $(\Delta)$; main $(+)$; lateral accretion $(X)$; stocks and circular intrusions $(\circ)$; final accretion $(\square)$

- os limites dos ciclos magmáticos não coincidem com os limites das fases magmáticas. Este fato indica um retardo entre as mudanças químicas que ocorreram nas câmaras magmáticas coletoras (expressas pelos ciclos magmáticos) e as mudanças no regime tectônico da colocação magmática (expressas pelas fases magmáticas sucessivas). Tal fato é corroborado pelas Figs. 3, 7, 8, 9 e 10;

- cada ciclo magmático compreende 3 a 5 impulsos magmáticos que cristalizam originando fácies magmáticas, as quais apresentam, ao mesmo tempo, características mineralógicotexturais específicas, mas cuja variação de fácies para fácies na sequência temporal de sua colocação determina tendências evolutivas definidas (Ferreira \& Wernick 1991). Entretanto, os dados químicos, quando tratados em diagramas multicatiônicos, revelam tanto tendências evolutivas contínuas nas fácies quimicamente expandidas (e que variam de fácies para fácies) quanto saltos composicionais de fácies para fácies, indicando que as fácies mais novas não são o produto do fracionamento de impulsos magmáticos precedentes durante sua fase de colocação (Wernick et al. 1993a);

- o número de impulsos magmáticos por ciclo magmático é compatível com o observado em outros complexos cálcioalcalinos múltiplos e compostos que, entretanto, podem apresentar um número de ciclos magmáticos mais elevado (Pitcher 1985).

Os dados químicos referentes ao Complexo Rapakivi São Francisco (Fig. 6) permitem a definição de dois ciclos magmáticos (Godoy \& Wernick 1992a). O primeiro reúne as unidades magmáticas $\mathrm{F}_{2}, \mathrm{~F}_{3}$ e $\mathrm{F}_{4}$ e o segundo as unida-
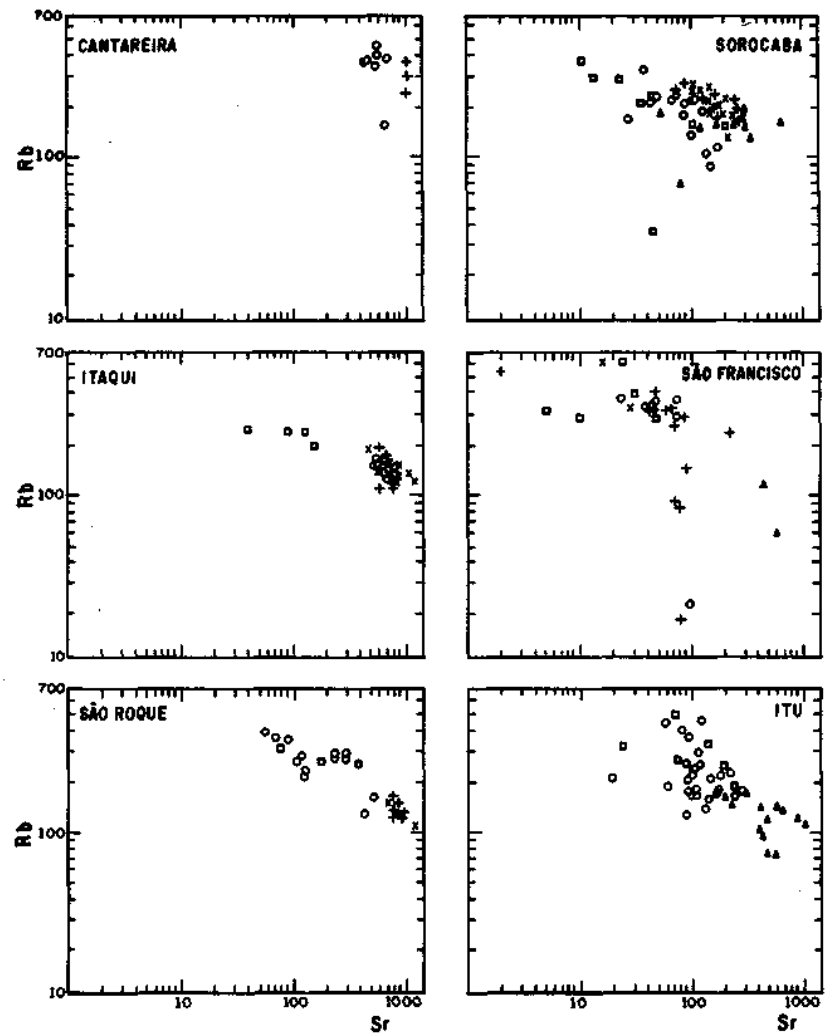

Figura 10 - Diagramas $\mathrm{Rb}$ x Sr para rochas das unidades magmáticas dos Complexos Granitóides Itaqui, São Roque, Cantareira, São Francisco, Sorocaba e Itu (Intrusão Cabreúva), agrupados por fases magmáticas. Fases: precoce (L); principal (+); acresção lateral (X); stocks $e$ intrusões circulares (०); acresção final (口) Figure $10-\mathrm{Rb} \times \mathrm{Sr}$ diagrams for rocks from magmatic units from the Itaqui, São Roque, Cantareira, São Francisco, Sorocaba e Itu (Cabreúva intrusion) granitoids complexes, assembled in magmatic phases. Phases: early $(\Delta)$; main $(+)$; lateral accretion $(\mathrm{X})$; stocks and circular intrusions $(\mathrm{O})$; final accretion $(\square)$

dês $\mathrm{F}_{6}, \mathrm{~F}_{7}$ e $\mathrm{F}_{8}$. A presença de um terceiro ciclo, correspondente à fase magmática precoce e representada pela unidade $F_{1}$, é fato questionável tendo-se em vista que esta unidade também poderia corresponder à fase magmática dos diques máficos, aqui representada por diques sinplutônicos desmembrados em enclaves e megaenclaves. Como o Complexo São Francisco reúne litologias muito ricas em sílica, a definição dos ciclos baseia-se primordialmente nos álcalis. Enquanto no primeiro ciclo os valores de $\mathrm{K}_{2} \mathrm{O}$ e $\mathrm{Na}_{2} \mathrm{O}$, respectivamente, crescem e decrescem gradualmete com a sucessão dos impulsos magmáticos, no segundo ciclo observa-se uma variação oposta.

A figura 6 mostra também os dados químicos referentes à variação composicional das 18 unidades magmáticas do Complexo Rapakivi Sorocaba. Este elevado número, o maior de todos os complexos granitóides aqui considerados, resulta do alçamento vertical diferenciado "em escada" de diversos blocos tectônicos ao longo de falhas normais transversais, que cortam o Complexo Sorocaba. Esta ampla exposição vertical mostra que a arquitetura do complexo assemelha-se a dos complexos múltiplos e compostos do Peru (Thorpe \& Francis 1979). O histograma dos dados químicos permite a definição de quatro ciclos magmáticos (Godoy \& Wernick 1992b). O primeiro compreende as unidades magmáticas $\mathrm{F}_{1}$ a $\mathrm{F}_{6}$, o segundo as unidades $\mathrm{F}_{7}$ a $\mathrm{F}_{11}, \mathrm{o}$ terceiro as unidades $\mathrm{F}_{12}$ e $\mathrm{F}_{13}$ e $\mathrm{o}$ último as unidades $\mathrm{F}_{16}, \mathrm{~F}_{17} \mathrm{e}$ Fjg Todas as unidades apresentam teores de $\mathrm{Na}_{2} \mathrm{O}$ aproxima- 
damente constantes e os diferentes ciclos se caracterizam por teores de $\mathrm{K}_{2} \mathrm{O}$ crescentes, constantes ou decrescentes.

Os dados químicos das unidades magmáticas da Intrusão Cabreúva, a maior das quatro intrusões centradas, que compõe o Complexo Rapakivi Itu (Fig. 6), definem três ciclos magmáticos para este granitóide pluriserial (Wernick et al. 1993b). O primeiro compreende as rochas cálcio-alcalinas pretéritas à implantação do complexo rapakivi, ora presentes sob forma de enclaves e megaenclaves, e reunidas na associação da fácies $\mathrm{F}_{1} \mathrm{O}$ segundo reúne as rochas subalcalinas potássicas das unidades $\mathrm{F}_{2}$ e $\mathrm{F}_{3}$, também presentes sob forma de enclaves e megaenclaves nas unidades mais jovens (Fig. 5). O terceiro ciclo reúne as rochas com tendências alcalinas das unidades $\mathrm{F}_{4}, \mathrm{~F}_{5}$ e $\mathrm{F}_{6}$ (Wemick et al. 1991). A variação na fonte genética dos impulsos magmáticos dos três ciclos é ressaltada pela figura 9.

Sobre os ciclos magmáticos dos complexos rapakivi aqui considerados, constata-se os mesmos aspectos gerais observados nos complexos cálcio-alcalinos e previamente mencionados. Cabe, entretanto, ainda destacar que os Granitóides Sorocaba, São Francisco e Itu, nesta sequência, apresentam teores crescentes de álcalis (Fig. 7) e teores decrescentes de $\mathrm{K}_{2} \mathrm{O}$ (Fig. 8) e que esta variação se correlaciona com idades decrescentes globais de colocação dos complexos (Godoy 1989, Wernick et al. 1993b).

Os dados aqui apresentados revelam que a arquitetura dos complexos e a presença de ciclos magmáticos independem de sua natureza serial (cálcio-alcalina ou rapakivi) e, conseqüentemente, as causas da recorrência devem ser procuradas num mecanismo comum de ascenção magmática. A associação dos complexos granitóides com falhas transcorrentes é sugestiva para que a ascensão se tenha dado por propagação de diques. Este mecanismo frequentemente leva ao desenvolvimento de câmaras magmáticas coletoras intra-crustais, nas quais operam mecanismos de fracionamento em estado essencialmente líquido e que são sucessivamente drenadas e recarregadas. Como as grandes zonas de cisalhamento que cortam o embasamento cristalino do Estado de São Paulo (Fig. 1) se vinculam à colisão oblíqua entre os blocos Paraná e São Francisco (Soares et al. 1990), é de se esperar que a história evolutiva das falhas transcorrentes mais expressivas (Taxaquara, Jundiuvira, Cubatão etc.) seja, em termos gerais, a mesma. Deste aspecto resulta, por exemplo, que todas as unidades magmáticas oriundas da fase magmática de colocação de stocks e intrusões circulares acham-se seccionadas por ralhas transcorrentes ligadas a um período de reativação tardio. Desta maneira, as reativações sucessivas nelas detectadas são essencialmente de mesma natureza e aproximadamente isócronas, o que explica a recorrência de um mesmo padrão de estruturação nos diferentes complexos aqui examinados, bem como a presença de sucessivos ciclos magmáticos.

CONCLUSÕES Do estudo comparativo das fases de acresção e dos ciclos magmáticos que constituem os Complexos Cálcio-Alcalinos Itaqui, São Roque e Cantareira e os Complexos Rapakivi Sorocaba, São Francisco e Itu, todos associados à falhas transcorrentes, resultam as seguintes conclusões:

- Todos os complexos considerados apresentam estruturação semelhante dada por uma fase magmática principal, precedida ou não por uma fase precoce, e seguida de uma fase de crescimento lateral dada por diques ou adições marginais, a qual se segue uma fase de colocação de stocks e bossas, e uma fase final de pequenos corpos locais, além de pegmatitos e/ou aplitos e adições laterais menores. A Intrusão Cabreúva, do Complexo Itu, representa a fase de stocks e bossas de colocação rasa na qual a estrutura circular preserva as fases precedentes apenas sob forma de enclaves e megaenclaves, estes até quilométricos (Wernick et al 1993c).

- Todos os complexos são constituídos por mais de um ciclo magmático que podem ser plurisseriais, caso do Complexo Itu, ou não (Wernick et al. 1991, 1993a, b, c). Nos Complexos Itaqui, Cantareira, São Roque e Sorocaba as fases magmáticas terminais são caracterizadas por um enriquecimento em turmalina (Godoy 1989, Ferreira 1991, Andrade 1993). Em todos os complexos os ciclos finais são mais ricos em álcalis que os precedentes (Figs. 4 e 6 ).

- Os diversos ciclos magmáticos dos complexos aqui considerados compreendem tanto unidades magmáticas quimicamente expandidas quanto restritas. Não existe correlação direta entre o teor medio de sílica das unidades magmáticas e sua variabilidade composicional. Também não é verificada uma variação sistemática na variabilidade composicional das unidades magmáticas de acordo com sua seqüenciação temporal num dado ciclo magmático (Figs. 4 a 6 ).

- Existem ciclos magmáticos com características distintas quanto ao comportamento dos álcalis. Em alguns tanto o $\mathrm{K}_{2} \mathrm{O}$ quanto o $\mathrm{Na}_{2} \mathrm{O}$ aumentam com a sucessão temporal das unidades magmáticas. Em outros, enquanto o $\mathrm{K}_{2} \mathrm{O}$ cresce, o $\mathrm{Na}_{2} \mathrm{O}$ decresce gradualmente, ou vice-versa. Ainda, em outros, enquanto um dos álcalis varia sistematicamente, o outro apresenta valores aproximadamente constantes (Figs. 4 e 6 ).

- Na maioria dos casos os ciclos magmáticos mais novos iniciam-se com termos litológicos mais básicos que os termos finais do ciclo precedente (Figs. 4 e 6 ).

- Em vários casos, não há coicidência entre os limites de fases e ciclos magmáticos. Tal fato indica a existência de uma defasagem temporal entre as mudanças nas condições tectônicas (retratadas nas fases magmáticas) e as mudanças químicas (dadas pelo início de um novo ciclo magmático). Tal fato reflete-se nas figuras 3, 7, 8, 9 e 10 .

- Entre os granitos rapakivi, a crescente alcalinidade que caracteriza a Sequência Sorocaba - São Francisco - Itu, sugere que a mesma corresponda, também, à ordem cronológica de sua colocação. Tal fato é corroborado pelo formato circular das intrusões que compõe o Complexo Itu; pelo controle do formato do Complexo São Francisco, pelas estruturas $\mathrm{D}_{3}$ e pelo caráter sin a tardi- $\mathrm{D}_{3}$ do Complexo Sorocaba (Godoy 1989).

- Os Complexos Itaqui, São Roque e Cantareira iniciaram a sua colocação antes dos Complexos Sorocaba, São Francisco e Itu (pois foram parcialmente afetados pela deformação $\mathrm{D}_{3}$ ), mas a presença da fase de colocação dos stocks e bossas em todos os complexos sugere que o término da colocação dos granitóides cálcio-alcalinos coincidiu temporalmente com a dos granitos rapakivi. Tal fato indica a coexistência temporal, durante certo período, entre os magmatismos cálcio-alcalinos e rapakivi.

- Todos os complexos foram afetados por reativações de falhas transcorrentes, às quais se vinculam. Os Complexos Itaqui, São Francisço e Itu indicam que as últimas reativações foram posteriores à fase de colocação dos stocks e bossas, uma vez que nestes granitóides estas estruturas estão seccionadas e deslocadas ao longo de falhas transcorrentes (Godoy 1989, Ferreira 1991, Galembeck 1991).

- O conjunto dos aspectos até agora considerado sugere uma vinculação entre as fases magmáticas e períodos de movimentação recorrentes ao longo das falhas transcorrentes. A colocação da fase magmática principal, muitas vezes com feições de injeção forçada, pode ser considerada como associada a feiçõ̃es pull apart ao longo das falhas trancorrentes (Hutton 1982, Guineberteau et al 1987). A persistência da movimentação levou a uma posterior deformação progressiva das massas já colocadas e propiciaram o desenvolvimento de fraturas tensionais que controlaram novas adições magmáticas laterais, bem como a intrusão de diques e plútons menores. Nova movimentação secciona e desloca as unidades magmáticas ligadas a fase de colocação desses stocks e bossas, bem como as unidades magmáticas precedentes. 
- A existência de sucessivos ciclos magmáticos com características químicas e tendências evolutivas distintas vinculadas a sucessivas fases magmáticas sugere a existência de câmaras magmáticas coletoras de pequena a média profundidade, sucessivamente drenadas e recarregadas e nas quais operam diferentes processos de modificações magmáticas. Tal fato indica a importância da caracterização destes processos na fase da residência magmática. A abordagem desta problemática, entretranto, é dificultada principalmente nos impulsos quimicamente expandidos, pela superposicão de novos processos na fase de cristalização final que obliteram, com maior ou menor intensidade, os processos que atuaram na fase da residência magmática.

Agradecimentos Os autores E. Wernick e A.C. Artur agradecem a FINEP (processo 4.3.90.0315.00) e ao CNPq (processos 50.0459/90-8 e 300319/81-9) pelos auxílios concedidos para a realização deste trabalho.

\section{REFERÊNCIAS BIBLIOGRÁFICAS}

ANDRADE, KRD. 1993. Complexo Granitóide São Roque, SP: Petrografia, Litoquímica e Tipologia de Zircão. Rio Claro. 156 p. (Dissertação de Mestrado, IGCE/UNESP).

ANDRADE, F.R.D.; ARTUR, A.C.; WERNICK, E. 1992. Geologia do Complexo Granitóide São Roque, SP. In: CONGR. BRÁS. GEOL., 37. São Paulo, 1991. Boletim dos Resumos.,. São Paulo, SBG. v. l, p. 350-351.

BALEY, R.A.; DALRYMPLE, G.B.; LANPHERE, M.A. 1976. Volcanism, structure and geochronology of Long Valley Caldera, Morro County, Califórnia. J. Geophys. Res., 81:725-744.

BUSSEL, M.A. \& PITCHER, W.S. 1985. The structural contrais of batholith emplacement. In: PITCHER, W.S.; ATHERTON, M.P.; COBBING, E.J. \& BEKINSALE, R.D. eds. Magmatism at a Plate Edge. The Peruvian Andes. New York, Wiley \& Sons. p. $167-176$.

CAMPBELL, I.H. \& TURNER, J.S. 1986. The influence of viscosity on fountains in magma chambers. J. Pétrol., 27:1-30

CASTRO, A. 1987. On granitoid emplacement and related structures. Geol. Rundsch., 76(1):101-124.

DANTAS, A.S.L. 1990. Geologia da Faixa São Roque e Intrusivas Associadas na Região entre São Paulo e Mairíporã, Norte de São Paulo SP. São Paulo. 217 p. (Dissertação de Mestrado, IG-USP).

EICHELBERGER, J.C. 1980. Vesiculatipn of mafic magma during replemishment of silic magma reservoirs. Nature, 288:446-450.

FERREIRA, C.J. 1991. Geologia, Petrografia e Tipologia de Zircão da Suite Inirusiva Itaqui, Barueri (SP). Rio Claro. 253 p. (Dissertação de Mestrado, IGCE/UNESP)

FERREIRA, C.J. \& WERNICK, E. 1991. Petrografia da Suíte Intrusiva Itaqui, SP. In: SIMP. GEOL. SUDESTE, 2. São Paulo, 1991. Atas... São Paulo, SBG/NSP-NRJ. p. 121-129.

GALEMBECK, T.M.B. 1991. Aspectos Geológicos, Petrográficos e Geoquímicos da Intrusão Cabreúva • Complexo Granitóide Itu (SP). Rio Claro. 195 p. (Dissertação de Mestrado, IGCE/UNESP).

GALEMBECK, T.M.B.; WERNICK, E.; ARTUR, A.C. 1991. Estruturação, faciologia e petrografia da Intrusão Cabreúva, Complexo Rapakivi Itu, SP. In: SIMP. GEOL. SUDESTE, 2. São Paulo, 1991. Atas... São Paulo, SBG/NSP-NRJ. p. 113-120.

GODOY, A.M. 1989. Caracterização Faciológica, Petrográfica e Geoqufimica dos Macicos Sorocaba e São Francisco, SP. São Paulo. $220 \mathrm{p}$. (Tese de Doutoramento, IG/USP)

GODOY, A.M. \& FIGUEIREDO, M.C.H. 1991a. Mapeamento faciológico e petrográfico dos Maciços Granitóides São Francisco e Pirapora (SP). In: SIMP. GEOL. SUDESTE, 2. São Paulo, 1991. Atas... São Paulo, SBG/NSP-RJ. p. 139-145.

GODOY, A.M. \& FIGUEIREDO, M.C.H. de 1991b. Caracterização faciológica e petrográfica do Maciço Granitóide Sorocaba (SP). In: SIMP. GEOL. SUDESTE, 2. São Paulo, 1991. Atas... São Paulo, SBG/NSPRJ.p. $131-138$

GODOY, A.M. \& WERNICK, E. 1992a. Arquitetura e evolucão magmática do Complexo Rapakivi São Francisco, SP. In: CONGR. BRAS. GEOL., 37. São Paulo, 1992. Boletim de Resumos Expandidos... São Paulo. v. 1, p. 332-333.

GODOY, A.M \& WERNICK, E. 1992b Arquitetura e ciclos maomáticos do Complexo Rapakivi Sorocaba, SP. In: CONGR. BRAS. GEOL., 37. São Paulo, 1992. Boletim de Resumos Expandidos... São Paulo, v. 1, p. $329-330$

GUINEBERTEAU, B.; BOUCHEZ, J.L.; VIGNERESSE, J.L. 1987. The Mortagne granite pluton (France) emplaced by pull-apart along a shear zone: structural and gravimetric arguments and regional implication. Geol. Soe. Am. Bull., 99:763-770.

HILDRETH, W. 1981. Gradients in silicic chambers: implications for lithospheric magmatism. J. Geophys. Rés., 86:10153-92.

HUTTON, D.H.W. 1982. A tectonic model for the emplacement of the Main Donegal Granite, NW Ireland. J. Geol. Soe. London, 139:615-631.

MARTIN, D.; GRIFFITHS, W; CAMPBELL, I.H. 1987. Compositional and thermal convection in magma chambers. Contrib. Mineral. Petrol., 36:465-475.
MARSH, B.D. 1982. On the mechanics of igneous diapirism, stoping and zone melting. Am. J. Sci., 282:808-855.

MIDDLEMOST, E.A.K. \& ROMEY, W.D. 1968. A graphic story of magmatic differentiation. Lithos, 1:242-263.

PASCHOALATTI, E.M.; VLACH, S.R.F.; AMARAL, G. 1987. Contribuicão ao conhecimento da Sufte Intrusiva Itu. In: SIMP. REG. GEOL., 6 . Rio Claro, 1987. Atas... São Paulo, SBG/NSP. v. 1, p. 47-62.

PITCHER, W.S. 1985. A multiple and composite batholith. In: PITCHER, W.S.; ATHERTON, M.P.; COBBING, E.J.; BECKINSALE, R.D. eds. Magmatism at a Plate Edge. The Peruvian Andes. New York, Wiley \& Sons. p. 93-101.

PITCHER, W.S. \& BUSSEL, M.A. 1985. Andean dyke swarms andesite in synplutonic relationship with tonalite. In: PITCHER, W.S.; ATHERTON, M.P.; COBBING, E.J.; BECKINSALE, R.D. eds. Magmatism at a Plate Edge. The Peruvian Andes. New York, Wiley \& Sons. p. 102-107.

PUPIN, J.P. 1980. Zircon and granite petrology. Contrib. Mineral Petrol, 73:207-220.

RAMBERG, H. 1981. Gravity, Deformation and the Earth Crust. 2 ed. New York, Academic Press. p. 452.

REGO, L.F.M. 1937. A geologia do Estado de São Paulo. Boi. Dep. Estr. Rod., 3(3):548-556.

REGO, L.F. M. \& SANTOS, T.D.S. 1938. Contribuição para o Estudo dos Granitos da Serra da Cantareira. São Paulo. 169 p. (Boletim 18).

RICE, A. 1985. The mechanism of the Mt. St. Helens eruption and speculation regarding soret effects in planetary dynamics. Geophys. Surv., 7:303-384

ROTHMAIER, R. 1994. Die Rapakivi Intrusionen Sguario, Campina do Veado und Pirituba: Hybrídgesteine und Magmen Mischung im Bundestaat São Paulo, Brasilien. Geologische Kartierung, Petrographie, Geochemie und Zirkonmorphologie. Alemanha. 99 p. (Dissertação de Mestrado, Eberhard - Karls - Universitat, Tübingen).

SHAW, H.R. 1980. Fracture mechanism of magma transport from the mantle to the surface - In: HARGRAVES, R.B. ed.Physics of Magmatic Processes, New Jersey, Princeton, Universit Press. p. 201-264

SHEINMANN, Yu. M. 1971. Tectonics and the Formation of Magmas. New York, Consulants Bureau. p. 452. (Tradução do russo por J. Paul Fitzsimmons).

SIBBET, B.S. 1988. Size depth and related structures of intrusions under stratovolcanoes and associated geothermal systems. Earth-Sci. Rev., 25:291-309.

SOARES, P.C.; FIORI, A.P.; CARVALHO, S.G. 1990. Tectônica colisional oblíqua entre o Bloco Paraná e a margem sul do Cráton São Francisco, no Macico Guaxupé. In: CONGR. BRAS. GEOL., 36. Natal, 1990. Anais... Natal, SBG. v. 7, p.63-79.

THORPE, R.S. \& FRANGIS, P.W. 1979. Petrogenetic relationships of volcanic and intrusive rocks of the Andes In: ATHERTON, M.P. \& TARNEY, J. ed. Origin of Granite Batholith. Geochemical Evidence. Cheshire, UK, Shiva Publ. p. 65-75.

WALKER, D. \& DELONG, S.E. 1982. Soret separation on mid-ocean ridge basalt magma. Contrib. Mineral. Petrol, 79:231-240.

WERNICK, E. 1983. Enclaves e seu significado geológico. Geociências, 2:17-36.

WERNICK, E. 1990. Zoneamento magmático regional de granitóides brasilianos no, Sudeste/Sul do Brasil: implicaçôes geotectônicas. In: CONGR. BRÁS. GEOL., 36. Natal, 1990. Anais... Natal, SBG. v. 4, p. 1668-1683.

WERNICK, E. \& FERREIRA, C.J. 1987. Um expressivo dique de enclaves no Granito Itaqui, arredores da cidade de São Paulo. In: SIMP. REG. GEOL., 6. São Paulo, 1987.Atas... São Paulo, SBG/ NSP. v. 1, p. 135-148.

WERNICK, E. \& FERREIRA, C.J. 1993. Estruturas, arquitetura e evolucão do Complexo Granitóide Itaqui, SP. Geociências, 12(1):89-109.

WERNICK, E.; WEBER-DIEFENBACH, K.; CORREIA, L.A.; CERQUEIRA, C. 1985. Os Granitos Mairiporẫ, Cantareira e Perus, arredores de São Paulo: dados químicos, tipologia de zircão e uma interpretação preliminar. In: SIMP. REG. GEOL., 5. São Paulo, 1985. Atas... São Paulo, SBG/SP. v. 1, p. 3-18. 
WERNICK, E.; FERREIRA, C.J.; HORMANN, P.K. 1993a. Evolução das unidades magmáticas do Complexo Granitóide Itaqui (PréCambriano Superior), Estado de São Paulo, Brasil: aspectos geológicos, petrográficos e geoquímicos (elementos maiores). Rev. Brás. Geoc., 23(3):274-281.

WERNICK, E.; FERREIRA, C.J.; HORMANN, P.K.; DUTRA, C.V.; 1993c. Viscosidade de magmas graníticos: uma abordagem através de elementos terras raras no Complexo Granitóide Itaqui, SP. Rev. Brás. Geoc., 23.

WERNICK, E; GALEMBECK, T.M.B; WEBER-DIEFENBACH, K 1991. Geoquímica e evolução magmática da Intrusão Cabreúva (Complexo Rapakivi Itu), SP, Brasil. In: CONGR. BRÁS. GEOL.,3 e
CONGR. GEOQ. DOS PAÍSES DE LÍNGUA PORTUGUESA, 1.

São Paulo, 1991. Resumos... São Paulo, SBG. v. 1, p. 294-297.

WERNICK, E.; GODOY, A.M.; GALEMBECK, T.M.B. 1993b. Fases

magmáticas e aspectos químicos dos complexos rapakivi Sorocaba, São

Francisco e Itu, SP: um estudob comparativo. Geociências, (no prelo).

MANUSCRITO A782

Recebido em 31 de agosto de 1993

Revisão do autor em 4 de agosto de 1994

Revisão aceita em 15 de agosto de 1994 